\title{
Medicare advocates decry medical tourism
}

See related editorial on page 971 and at www.cmaj.ca/lookup/doi/10.1503/cmaj.141047

$\mathrm{M}$ edical tourism conjures up destinations like India and Brazil, but two Toronto hospitals want foreigners to think of Canada for surgeries and cancer treatment. Sunnybrook and University Health Network (UHN) hospitals in Toronto, Ontario, are accepting — and charging - foreign patients, yet refusing to disclose key details about their medical tourism programs, which has raised red flags among medicare advocates.

Sunnybrook Hospital launched a program to treat medical tourists in January, while UHN formalized its program three years ago. Under the programs, medical tourists travel specifically for treatment and pay much higher rates than Canadian patients - which is a far cry from the humanitarian or emergency treatment of international visitors.

Canadian Doctors for Medicare, the Registered Nurses' Association of Ontario, the Association of Ontario Midwives, the Association of Ontario Health Centres and the Medical Reform Group have called on the provincial government to ban medical tourism, which they argue draws resources away from Ontario patients and lays the foundation for a broader two-tier system.

So far this year, three international patients have been treated at Sunnybrook, and about 75 patients have received care at UHN.

Media relations at Sunnybrook declined an interview, saying it was "too early" to talk about their experience.

Dr. Nizar Mahomed, the managing director of UHN's international programs, says that medical tourism "allows us to generate revenue and to open up additional beds and [operating room] time for Ontario patients."

But as to how much money from international programs is funnelled back to health care for Ontarians, "that's proprietary information," Mahomed says.

"If [UHN and Sunnybrook] have a meaningful model, they ought to be able to defend it," says Leigh Turner,

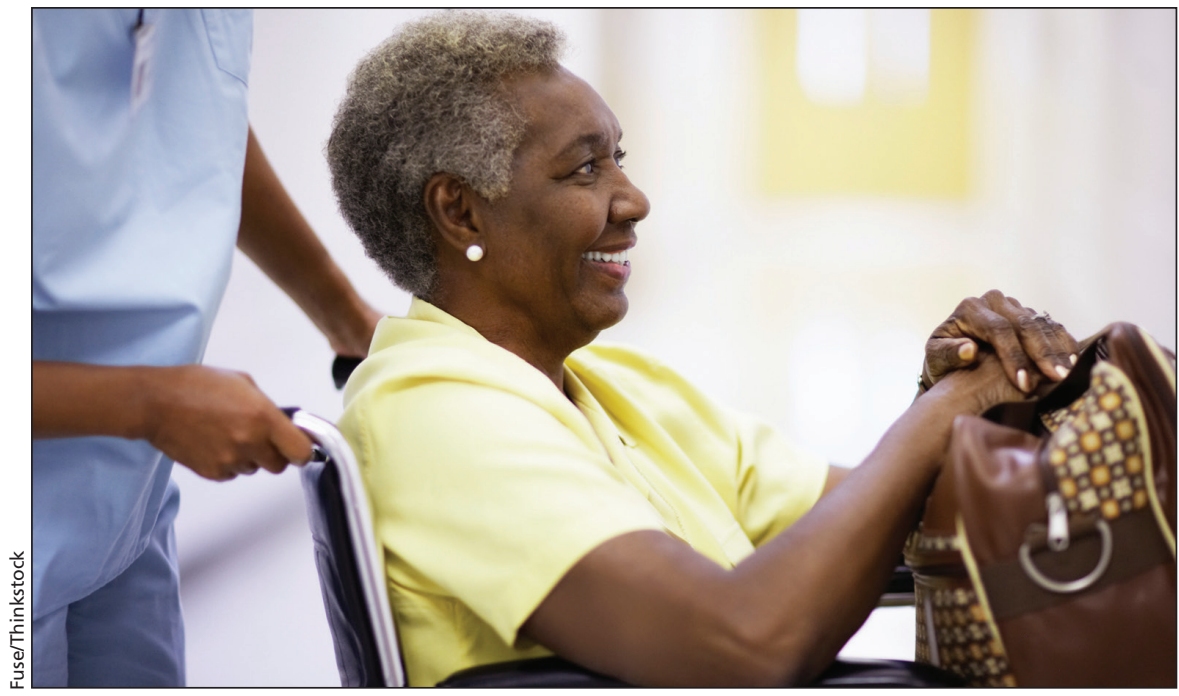

The international patients pay more than the provincial insurance scheme, but no one will say how much more.

an associate professor at the Center for Bioethics at the University of Minnesota in Minneapolis who published an article in Healthcare Policy on the dangers of medical tourism in Canada. "It's not enough for [hospital managers] to pat everyone on the head and say not to worry."

The Ministry of Health is reviewing the hospitals' medical tourism programs to ensure access for Ontario patients isn't affected, but Doris Grinspun, chief executive officer of the Registered Nurses' Association of Ontario, says that's already happened.

Her nurses have reported that Ontario patients' surgeries have been cancelled so that UHN doctors could treat international patients instead, for whom they receive more money. When asked about the cancellations, Mahomed says, "I'm not aware of any such example."

Health workers are paid more to treat medical tourists because they are working on their own time "instead of taking vacation time," Mahomed says. He wouldn't say how much more, but did say international patients are charged about double the public rate.

However, Monika Dutt, chair of
Canadian Doctors for Medicare, counters that, if medical tourism increases, doctors could decide to devote more time to treating international patients.

Although medical tourism has been previously tried in Montréal and was once proposed by a former $\mathrm{BC}$ health minister, the Toronto hospitals currently appear to be alone in their pursuit of the revenue strategy.

Critics of the medical tourism programs worry they will create a two-tier system for Canadian patients.

"If we're going to allow international patients to purchase health care, how defensible is it to say 'If you're a Canadian citizen, you're barred from going through that door?'” asks Turner.

Mahomed says operating rooms are only being used for international patients when they would otherwise be empty, but Turner points out Ontario patients are on wait lists for orthopedic surgeries and other treatments being offered to international patients at UHN. "Wouldn't it be better if we were pumping more money into our health care system to make sure the [operating] rooms were used?" Wendy Glauser, Toronto, Ont.

CMAJ 2014. DOI:10.1503/cmaj.109-4874 